\title{
A UNIVERSALIZAÇÃO DO DIREITO À VIDA E À DIVERSIDADE CULTURAL
}

\section{A UNIVERSAL RIGHT TO LIFE AND CULTURAL DIVERSITY}

\author{
Ivanaldo SANTOS ${ }^{1}$ \\ Patrícia Diógenes de $\mathrm{MELO}^{2}$
}

Artigo recebido em: 10/05/2016

Artigo aprovado em: 23/08/2016

\begin{abstract}
RESUMO: O direito a vida é um tema atual e que vem sendo debatido no âmbito da teoria do direito e das ciências humanas. O objetivo do artigo é abordar a universalização do direito à vida, analisando a questão frente à diversidade cultural e legislativa entre os países. Para alcançar o objetivo, o artigo foi dividido em quatro partes, sendo elas: Sobre os direitos humanos; Dignidade da pessoa humana; $\mathrm{O}$ direito humano à vida e $\mathrm{A}$ universalização dos direitos humanos. Por fim, afirma-se que na atualidade a proteção e garantia dos direitos humanos tem sido falha e que se observam vários casos de atentados a esses direitos, principalmente no tocante ao direito à vida, pois além de falhar na proteção falha-se também na educação para a vida e na punição dos indivíduos e das estruturas sociais culpadas pela violação do direito universal à vida.
\end{abstract}

\footnotetext{
${ }^{1}$ Filósofo, Pós-Doutorado em estudos da linguagem pela USP, Doutor em estudos da linguagem pela UFRN, professor do Departamento de Filosofia e do Programa de Pós-Graduação em Letras da Universidade do Estado do Rio Grande do Norte (UERN). E-mail: ivanaldosantos@yahoo.com.br

${ }^{2}$ Bacharel em Ciências Jurídicas e Sociais pela Universidade Federal de Campina Grande (UFCG), especialista em Direito Processual Civil pela UFCG e atualmente é mestranda no Programa de Pós-Graduação em Ensino (PPGE) da Universidade do Estado do Rio Grande do Norte (UERN).

E-mail: patricia_diogenes05@hotmail.com
} 
PALAVRAS-CHAVE: Direito à vida. Direitos humanos. Universalização.

ABSTRACT: The right to life is a current topic which has been debated in the context of the theory of law and the humanities. The objective of this paper it is to approach the universality of the right to life analyzing the issue on the cultural and legislative diversity among countries. To achieve the goal, the article was divided into four parts, as follows: On human rights; Dignity of human person; The human right to life and The universality of human rights. Ultimately, it is stated that nowadays the protection and guarantee of human rights has been failure and it is observed several cases of attacks on these rights, especially regarding the right to life, as well as failing in protecting it also fails in education for life and in the punishment of individuals and social guilty structures for violating the universal right to life.

KEYWORDS: Right to life. Human rights. Universality. 


\section{Introdução}

O presente trabalho trata-se de uma pesquisa bibliográfica, baseado na doutrina e na legislação pertinente aos direitos humanos. $O$ objetivo do artigo é abordar a universalização do direito à vida, analisando a questão frente à diversidade cultural e legislativa entre os países. O interesse pelo tema partiu, dentre outros pontos fundamentais, da atual discussão e das tentativas de garantia dos direitos humanos por parte do Estado e de diversas estruturas e matrizes da sociedade civil.

Para alcançar o objetivo, o artigo foi dividido em quatro partes, sendo elas: Sobre os direitos humanos; Dignidade da pessoa humana; O direito humano à vida e A universalização dos direitos humanos.

Na primeira parte realiza-se uma reflexão sobre a necessidade dos direitos humanos. Essa reflexão apresenta uma breve síntese da história do problema, síntese que vai desde a antiguidade até a sociedade contemporânea. A sua principal fundamentação teórica é Ramos (2014) e o documento Direitos Humanos na Administração da Justiça publicado pela International Bar Association. Na segunda parte apresenta-se o conceito e a importância da discussão sobre a dignidade da pessoa humana. Nessa parte, o fundamento teórico central é a clássica discussão realizada por Fukuyama (2003), e Brakemeier (2002), e os comentários de autores contemporâneos, como Zilles (2012) e Agostini (2015). Além disso, trabalha-se com a Declaração Universal dos Direitos Humanos e a Constituição Federal brasileira.

$\mathrm{Na}$ terceira parte apresenta-se a discussão sobre o fundamental direito humano à vida. Como fundamento teórico, encontram-se a Declaração Universal dos Direitos Humanos, a Constituição Federal brasileira, o clássico texto de Taureck (2007) e os comentários de Ramos (2014) e Santos (2014). Na quarta e última parte realiza-se uma discussão sobre a universalização dos humanos tendo por base o fundamental direito à vida. O fundamento teórico da discussão é o documento Direitos humanos e pluralismo cultural emitido, em 2006, pelo Conselho Nacional de Pesquisa e Pós-graduação em Direito (CONPEDI), a Declaração de Viena e os comentários de Torres (2010) e Menai (1997).

Por fim, à guisa de conclusão, se reconhece a relevância do princípio fundamental do direito à vida e a necessidade de se propagar um movimento pela sua universalização, assegurando que cada indivíduo tenha sua vida protegida e resguardada em qualquer território, independente da nação a qual 
pertença. Ao mesmo tempo, se reconhece que na atualidade a proteção e garantia do princípio fundamental do direito à vida tem sido falha e se observam vários casos de atentados a esse direito, pois além de falhar na proteção falha-se também na educação para a vida e na punição dos indivíduos e das estruturas sociais culpadas pela violação do direito universal a vida.

\section{Sobre os direitos humanos}

Todo direito se traduz numa faculdade de exigir de um terceiro, seja o Estado ou o particular, de cumprir determinada obrigação. Os direitos humanos se baseiam num conjunto de direitos essenciais para que o indivíduo goze de uma vida digna. Esses direitos são, assim, valores essenciais que estão protegidos em diversos documentos como constituições, tratados e convenções nacionais e internacionais.

De acordo com Ramos (2014) os direitos humanos apresentam quatro características essenciais. A primeira delas é a universalidade ao se reconhecer que esses direitos são direitos de todos e que não existe uma classe de pessoas superior à outra. A segunda é a essencialidade, a qual se traduz na indispensabilidade desses direitos, não é possível abrir mão deles. A terceira é a superioridade, pois esses direitos estão acima de qualquer outra norma, não sendo possível sacrificar um direito humano em obediência a qualquer legislação que seja, sempre que direitos humanos estiverem envolvidos na questão eles devem prevalecer. A quarta e última é a reciprocidade desses direitos, pois todos são titulares desses direitos e ao mesmo tempo têm o dever de respeitar os direitos dos demais.

Ainda de acordo com Ramos (2014), o primeiro direito basilar é o direito a ter direitos:

Arendt e, no Brasil, Lafer sustentam que o primeiro direito humano, do qual derivam todos os demais, é o direito a ter direitos. No Brasil, o STF adotou essa linha ao decidir que "direito a ter direitos: uma prerrogativa básica, que se qualifica como fator de viabilização dos demais direitos e liberdades" (ADI 2.903, Rel. Min. Celso de Mello, julgamento em $1^{\circ}$-12-2005, Plenário, DJE de 19-9-2008) (RAMOS, 2014, p. 24).

Todo Indivíduo tem direitos e deve conviver com os direitos dos ou- 
tros, os quais estão alicerçados no princípio da dignidade da pessoa humana, pelo qual todos os seres humanos têm o direito de serem respeitados, independente de quaisquer condições.

Desde a Bíblia é possível identificar no Antigo e no Novo testamento passagens que recomendam o amor e o cuidado com o próximo, a exemplo da passagem do livro de Deuteronômio 24, 17 "Não perverterás o direito do estrangeiro nem do órfão; nem tomarás em penhor o vestido da viúva". Com isso, é possível se afirmar que a religião judaico-cristã é uma das fortes influências na origem e no estabelecimento do regime de proteção dos direitos humanos.

$\mathrm{Na}$ Idade Média surgem as primeiras reivindicações por liberdade e protestos contra o poder absoluto dos reis como a Carta Magna de 1215 que estabelecia direitos e garantias contra os desmandos do monarca inglês João Sem Terra. Ressaltando-se que esses direitos eram garantidos apenas para a elite política inglesa, mas foi um passo importante para a história dos direitos humanos.

Apesar de seu foco nos direitos da elite fundiária da Inglaterra, a Magna Carta traz em seu bojo a ideia de governo representativo e ainda direitos que, séculos depois, seriam universalizados, atingindo todos os indivíduos, entre eles o direito de ir e vir em situação de paz, direito de ser julgado pelos seus pares [...] acesso à justiça e proporcionalidade entre o crime e a pena (RAMOS, 2014, p. 32).

Posteriormente, com o declínio da Idade Média e o surgimento do renascimento deu origem ao poder fortemente centralizado na figura do rei nos Estados absolutistas. Passa-se do domínio da Igreja e dos senhores feudais para o domínio dos reis, fato este que não garantiu a observância dos direitos dos indivíduos. Por exemplo, na Inglaterra, no século XVII, começa-se a questionar esse poder absoluto através da Petition of Rights de 1628, a qual estabelecia a proibição do rei de criar impostos sem autorização do parlamento inglês. Com isso, percebe-se a intenção de se proteger os interesses de uma classe em especial. Outro exemplo é a expedição do Habeas Corpus Act no ano de 1679, um documento que garantia direitos aos que fossem injustamente presos. Após dez anos da promulgação do Habeas Corpus Act, ou seja, em 1689 é criada a Bill of Rights, uma declaração de direitos que restringiu o poder absoluto do monarca inglês, preconizando a supremacia da vontade da lei sobre a vontade do rei.

Pouco mais de um século depois houve a criação da primeira consti- 
tuição do mundo moderno, a constituição norte-americana em 1787, expedida na Convenção de Filadélfia, após a independência das colônias do domínio britânico. Dois anos após este fato, em 1789, é criado o documento considerado um marco para a proteção dos direitos humanos. Trata-se da Declaração Francesa dos Direitos do Homem e do Cidadão, como consequência da Revolução Francesa, a qual propagou a liberdade e a igualdade como direitos inerentes de todo e qualquer indivíduo.

\begin{abstract}
A Declaração Francesa dos Direitos do Homem e do Cidadão proclamou os direitos humanos a partir de uma premissa que permeará os diplomas futuros: todos os homens nascem livres e com direitos iguais. Há uma clara influência jusnaturalista, pois, já no seu início, a Declaração menciona "os direitos naturais, inalienáveis e sagrados do homem" (RAMOS, 2014, p. 38).
\end{abstract}

É importante ressaltar que esta declaração defendia os direitos dos indivíduos considerados isoladamente, sem observar que o homem vive em sociedade e não pode ser dissociado dela. A partir dessa declaração, passou-se a reivindicar a inclusão dos direitos sociais, tais como: a educação, a saúde e a assistência social. Essa reivindicação influenciou a edição de constituições, reconhecendo tais direitos, em vários países.

A preocupação com a defesa dos direitos humanos se intensificou após a Segunda Guerra Mundial (1939-1945), culminando com a criação da Organização das Nações Unidas (ONU), cuja carta de criação assim determina no Artigo 55: "O respeito universal e efetivo dos direitos humanos e das liberdades fundamentais para todos, sem distinção de raça, sexo, língua ou religião". Nesse recorte, percebe-se a questão da universalização desses direitos a ser tratada mais a frente neste trabalho.

Essa carta da ONU foi de grande expressividade, contudo não elencou quais os direitos humanos que seriam considerados essenciais. Isso só veio ocorrer com a expedição da Declaração Universal de Direitos Humanos em 10 de dezembro de 1948, na cidade de Paris, a qual enumera os direitos humanos reconhecidos no âmbito internacional.

A Declaração Universal reconhece direitos civis, culturais, econômicos, políticos e sociais e, embora não se trate de um documento legalmente vinculatório per se, uma vez que o mesmo foi adotado por meio de uma deliberação da Assembléia Geral, os 
princípios nela contidos são atualmente considerados como sendo legalmente vinculatórios para os Estados, tanto como direito internacional consuetudinário, ou como princípios gerais de direito, ou como princípios fundamentais de humanidade (INTERNATIONAL BAR ASSOCIATION, 2010, p. 35).

Dessa forma, fica evidenciada a grande influência dessa declaração nos ordenamentos jurídicos de várias nações que a tomam como parâmetro em suas decisões. A Declaração Universal de Direitos Humanos estabelece em seu Artigo $1^{\circ}$ que "Todos os seres humanos nascem livres e iguais, em dignidade e direitos", enfatizando a necessidade de proteger a dignidade da pessoa humana para que possa exercer os direitos garantidos num Estado Democrático.

Os direitos fundamentais são direitos que visam à manutenção da vida humana de forma livre e digna. Pode-se afirmar que são um conjunto institucionalizado de direitos e garantias do ser humano que tem por finalidade básica o respeito à sua dignidade, por meio de sua proteção contra o arbítrio do poder estatal e o estabelecimento de condições mínimas de vida e desenvolvimento da personalidade humana.

Tais prerrogativas são tuteladas pelas constituições de diversos países, as quais têm como suporte a Declaração Universal de Direitos Humanos de 1948. Tais direitos, que garantem a dignidade da pessoa humana, não ficaram inertes ao longo do tempo e foram se transformando de acordo com os anseios da sociedade. São os mesmos classificados em quatro gerações, ou dimensões, de acordo com o bem tutelado.

Cada geração foi associada, na Conferência proferida por Vasak, a um dos componentes do dístico da Revolução Francesa: "liberté, egalité et fraternité" (liberdade, igualdade e fraternidade). Assim, a primeira geração seria composta por direitos referentes à "liberdade"; a segunda geração retrataria os direitos que apontam para a "igualdade"; finalmente, a terceira geração seria composta por direitos atinentes à solidariedade social ("fraternidade") (RAMOS, 2014, p. 49).

Assim, os denominados direitos de primeira geração (direitos civis e políticos) - que compreendem as liberdades clássicas, negativas ou formais - realçam o princípio da liberdade, protegendo o indivíduo contra a atuação abusiva do Estado. Os direitos de segunda geração (direitos econômicos, sociais 
e culturais) - que se identificam com as liberdades positivas, reais, concretas acentuam o princípio da igualdade, ao contrário da primeira geração, começouse a exigir um papel ativo do Estado na concretização de condições mínimas de sobrevivência aos indivíduos, como o direito à saúde, à educação, à habitação, à previdência social etc.

Os direitos de terceira geração, que materializam poderes de titularidade coletiva atribuídos genericamente a todas as formações sociais, a exemplo do direito à paz, à autodeterminação dos povos, ao meio ambiente equilibrado dentre outros. São direitos que consagram o princípio da solidariedade e constituem um momento importante no processo de desenvolvimento, expansão e reconhecimento dos direitos humanos, caracterizados enquanto valores fundamentais indisponíveis, pela nota de uma essencial inexauribilidade.

O Supremo Tribunal Federal utiliza a teoria geracional, com a seguinte síntese: "os direitos de primeira geração (direitos civis e políticos) - que compreendem as liberdades clássicas, negativas ou formais - realçam o princípio da liberdade e os direitos de segunda geração (direitos econômicos, sociais e culturais) - que se identifica com as liberdades positivas, reais ou concretas - acentuam o princípio da igualdade, os direitos de terceira geração, que materializam poderes de titularidade coletiva atribuídos genericamente a todas as formações sociais, consagram o princípio da solidariedade e constituem um momento importante no processo de desenvolvimento, expansão e reconhecimento dos direitos humanos, caracterizados, enquanto valores fundamentais indisponíveis, pela nota de uma essencial inexauribilidade" (MS 22.164, Rel. Min. Celso de Mello, julgamento em 30-10-1995) (RAMOS, 2014, p. 50).

Ao final do século XX, alguns estudiosos, a exemplo de Paulo Bonavides, defendem uma quarta geração de direitos humanos, resultantes da globalização desses direitos e se traduziriam no direito à participação democrática, direito ao pluralismo, limitação às manipulações de material genético e outros direitos.

Na verdade, atualmente entende-se que o correto não é classificá-los em gerações, o que dá uma ideia de algo ultrapassado e que posteriormente fora substituído, mas sim, em dimensões, pois os direitos não se esgotam, são dinâmicos e estão presentes na vida dos indivíduos, nas relações destes com os demais e com o Estado. Pelo acima exposto, essas dimensões de direitos tutelaram os ideais da Revolução Francesa: Liberdade, Igualdade e Fraternidade. 


\section{Dignidade da pessoa humana}

Os seres humanos se diferem, entre si, por diversos e múltiplos fatores. Entre eles é possível citar, por exemplo, a cor da pele, a classe social, as diferenças sexuais e as diferenças socioculturais. No entanto, existe um elo, um ponto comum entre os seres humanos. Esse elo é a dignidade da pessoa humana.

Sobre a dignidade como sendo o elo comum entre os seres humanos, afirma-se:

O que a igualdade de reconhecimento implica é que, quando despimos uma pessoa de todas as suas características contingentes e acidentais, resta sob isso uma qualidade humana essencial que é merecedora de certo nível mínimo de respeito - chama-se Fator $X$. A cor da pele, a aparência [física], a classe social e a fortuna, o gênero [sexual], a bagagem cultural e até os talentos naturais de uma pessoa são todos acidentes de nascimento relegados à classe de características não essenciais (FUKUYAMA, 2003, p. 158).

Apesar do ser humano possuir um número gigantesco de diferenças, nenhum desses fatores representa o que existe de mais essencial e característico do gênero humano. O que realmente representa a espécie humana é o fato de que "todos os seres humanos são, de fato, iguais em dignidade" (FUKUYAMA, 2003, p. 159).

A dignidade é o amplo conjunto de coisas, materiais e imateriais, que tornam o ser humano mais nobre, excelente, honrado e desejoso de melhorar a si mesmo, o outro, o seu próximo, a sociedade e a natureza. Por causa disso, a dignidade, em si mesma, "não pode ser demonstrada" (BRAKEMEIER, 2002, p. 16). Ela é essencialmente um valor e um princípio ético que orienta o ser humano a experimentar novas e mais humanas condições existenciais. É por causa disso que a "vida humana não perde sua dignidade quando afetada pela demência [pela doença] ou quando dormimos, pois a autonomia não é o único fundamento de sua dignidade" (ZILLES, 2012, p. 53).

Como bem observa Agostini (cf. 2015, p. 42), é preciso, de alguma forma, ter consciência do valor incomparável da vida humana, o que torna o ser humano o primeiro e fundamental caminho que se deve, de alguma forma, encontrar. Por isso, deve-se afirmar que a vida humana tem um valor incomparável, sendo, por isso, inviolável.

O preâmbulo da Declaração Universal de Direitos Humanos faz referência 
à dignidade atestando a sua indispensabilidade. A Constituição Federal brasileira, por sua vez, fazendo eco a Declaração Universal de Direitos Humanos, alçou a dignidade da pessoa humana ao patamar de princípio fundamental no Artigo $1^{\circ}$, III, reafirmando o valor da pessoa humana e a sua dignidade. Na verdade, este princípio é o sustentáculo de todos os demais direitos humanos a serem exercidos pelos indivíduos dentro do Estado democrático de direito. Um país que não assegure a dignidade da pessoa humana não pode pretender fundar um ordenamento jurídico.

Art. $1^{\circ}$ A República Federativa do Brasil, formada pela união indissolúvel dos Estados e Municípios e do Distrito Federal, constitui-se em estado democrático de Direito e tem como fundamentos. [...] III - a dignidade da pessoa humana.

Tem-se, pois por Princípio da Dignidade da Pessoa Humana um valor espiritual e moral inerente à pessoa, que se manifesta singularmente na autodeterminação consciente e responsável da própria vida e que traz consigo a pretensão ao respeito por parte das demais pessoas. Com isso, constituindo-se um mínimo invulnerável que todo estatuto jurídico deve assegurar, de modo que, somente excepcionalmente, possam ser feitas limitações ao exercício dos direitos fundamentais, mas sempre sem menosprezar a necessária estima que merecem todos os indivíduos enquanto seres humanos.

Com São Tomás de Aquino, há o reconhecimento da dignidade humana, qualidade inerente a todos os seres humanos, que nos separa dos demais seres e objetos. São Tomás de Aquino defende o conceito de que a pessoa é uma substância individual de natureza racional, centro da criação pelo fato de ser imagem e semelhança de Deus. Logo, o intelecto e a semelhança com Deus geram a dignidade que é inerente ao homem, como espécie (RAMOS, 2014, p. 65).

O Princípio da Dignidade da Pessoa Humana é uma característica inerente ao indivíduo e que o diferencia dos demais, protegendo-o de todo e qualquer tratamento discriminatório ou degradante. O referido princípio apresenta duas concepções: a primeira prevê como um direito individual protetivo, em relação ao Estado e em relação aos demais indivíduos. A segunda estabelece um dever fundamental de tratamento igualitário aos próprios 
semelhantes, ou seja, respeitar a dignidade do seu semelhante como é exigido pelo texto constitucional.

Diante da dignidade da pessoa humana, o Estado possui dois deveres, o primeiro é o dever de impor limites à atuação dos poderes públicos para que não venham a ferir a dignidade dos indivíduos através de atos abusivos. O segundo dever é o de garantia dessa dignidade, promovendo as condições necessárias para a sua concretização.

\section{$4 \mathrm{O}$ direto humano à vida}

A Declaração Universal de Direitos Humanos assegura em seu Artigo $3^{\circ}$ que todo o homem tem direito à vida. Esse é um direito humano a ser assegurado por todas as nações membros da ONU, de acordo com o que consta no preâmbulo: "Que os Estados Membros se comprometeram a promover, em cooperação com as Nações Unidas, o respeito universal aos direitos e liberdades fundamentais do homem e a observância desses direitos e liberdades".

Sobre o princípio do direito à vida, Taureck (2007) afirma que se trata do princípio básico e norteador de toda ação humana. Sem esse princípio, as ações e a cultura humana correrão risco de serem violadas e até mesmo de desaparecer.

No âmbito nacional, o que se observa é que a Constituição Federal brasileira, nos Títulos: I - Dos Princípios Fundamentais - e II - Dos Direitos e Garantias Fundamentais, que vão do Artigo $1^{\circ}$ ao Artigo $16^{\circ}$ adotou amplamente as disposições da Declaração Universal de Direitos Humanos. Em relação ao direito à vida, assim dispõe no Artigo 50: “Todos são iguais perante a lei, sem distinção de qualquer natureza, garantindo-se aos brasileiros e aos estrangeiros residentes no País a inviolabilidade do direito à vida". Assegurando que esse é um direito inviolável, alçado ao patamar de garantia fundamental. De acordo com Ramos (2014), o direito à vida engloba vários aspectos como a seguir mencionado:

O direito à vida engloba diferentes facetas, que vão desde o direito de nascer, de permanecer vivo e de defender a própria vida e, com discussões cada vez mais agudas em virtude do avanço da medicina, sobre o ato de obstar o nascimento do feto, decidir sobre embriões congelados e ainda optar sobre a própria morte. Tais discussões envolvem aborto, pesquisas científicas, suicídio assistido e eutanásia, suscitando a necessidade de dividir a proteção à vida em dois planos: a dimensão vertical e a dimensão horizontal (RAMOS, 2014, p. 423; itálicos no original). 
No plano vertical à proteção do direito à vida consiste em defender este direito nos vários estágios do desenvolvimento humano, da fecundação até a morte, protegendo este direito da intervenção de terceiros, como, por exemplo, de abusos por parte do poder estatal. No plano horizontal, por sua vez, se refere à qualidade de vida usufruída pelo ser humano. Um direito deesfrutado através do direito à saúde, à educação, à assistência social, ao meio ambiente equilibrado, enfim, todas as garantias para uma condição de vida digna. Este plano, inclusive, também pode ser observado na Declaração Universal de Direitos Humanos no Artigo 25:

I) Todo o homem tem direito a um padrão de vida capaz de assegurar a si e a sua família saúde e bem estar, inclusive alimentação, vestuário, habitação, cuidados médicos e os serviços sociais indispensáveis, e direito à segurança em caso de desemprego, doença, invalidez, viuvez, velhice ou outros casos de perda de meios de subsistência em circunstâncias fora de seu controle. II) A maternidade e a infância tem direito a cuidados e assistência especiais. Todas as crianças, nascidas dentro ou fora do matrimônio, gozarão da mesma proteção social (UNESCO, 1998).

Ainda com base em Ramos (2014), o direito à vida se traduz em obrigações a serem assumidas pelo Estado, quais sejam: a) A obrigação de respeito - traduzindo-se no imperativo das autoridades estatais não violarem a vida de outrem; b) A obrigação de garantia - proteger a vida do indivíduo contra atos de terceiros e a consequente punição dos seus violadores e c) A obrigação de tutela - que é a obrigação de oferecer uma vida digna, assegurando-se as condições mínimas de existência do indivíduo.

É preciso ter consciência, como observa Santos (cf. 2014, p. 58), que o direito à vida não pode ser um projeto passageiro, um modismo intelectual ou uma proposta efêmera e até mesmo populista de política do Estado. Esse é o direito fundamental, sem o qual qualquer outro direito não pode ser pensado, questionado e conquistado pelo cidadão.

É necessário que seja enfatizado, como realiza Taureck (cf. 2007, p. 57), o fato do direito à vida envolver todos os grupos sociais, estruturas culturais e modalidades de indivíduos. Nenhum indivíduo está fora do direito à vida. Pelo contrário, da concepção até o envelhecimento e a morte, todos os indivíduos 
estão envolvidos e protegidos pelo direito à vida.

A Constituição Federal brasileira não determina a partir de quando o direito à vida passa a ser tutelado, mas de acordo com a Convenção Americana de Direitos Humanos, Artigo 4.1, esse direito deve ser protegido desde a concepção. No Brasil, o Superior Tribunal Federal (STF) dispõe da seguinte forma sobre este ponto:

A potencialidade de algo para se tornar pessoa humana já é meritória o bastante para acobertá-la, infraconstitucionalmente, contra tentativas levianas ou frívolas de obstar sua natural continuidade fisiológica [...]. O Direito infraconstitucional protege por modo variado cada etapa do desenvolvimento biológico do ser humano. Os momentos da vida humana anteriores ao nascimento devem ser objeto de proteção pelo direito comum (Voto do Min. Ayres Britto, ADI 3.510, Rel. Min. Ayres Britto, julgamento em 29-5-2008, Plenário, DJE de 28-5-2010) (RAMOS, 2014, p. 424).

Dessa forma, o direito à vida deve ser protegido desde a fase uterina. $\mathrm{O}$ Artigo $2^{\circ}$ do Código Civil brasileiro se preocupou com tal questão da proteção à vida desde a fase uteriana. Por isso, determina: "A personalidade civil da pessoa começa do nascimento com vida; mas a lei põe a salvo, desde a concepção, os direitos do nascituro". Por isso, se apreende que para se exercer plenamente os atos civis, primeiramente é necessário nascer com vida. Entretanto o nascituro, ou seja, aquele que ainda vai nascer tem seus direitos reconhecidos e assegurados, dentre os quais é possível mencionar o direito à herança.

A Carta Magna brasileira também não estabelece nada acerca do término da vida, ou seja, da morte do indivíduo. Tal tema só foi explicitado no Código Civil, o qual prevê em seu Artigo $6^{\circ}$ que a existência da pessoa natural tem fim com a morte. Por sua vez, a morte deve ser a morte encefálica. Trata-se de um critério adotado na Lei de Transplantes - Lei nº 9.434/97 (cf. BRASIL, 1997). Por isso, é a condição necessária para que se autorize, no caso do Brasil, a retirada de órgãos e tecidos para fins de transplante ou tratamento.

Além disso, ressalte-se que o Brasil proíbe penas capitais, ou seja, punições que retirem totalmente o direito à vida do indivíduo. Isso pode ser verificado, por exemplo, no que dispõe o Artigo 5 , XLVII da Constituição Federal, como a pena de morte, salvo em caso de guerra declarada, e neste caso cabe ao Código Penal Militar estabelecer sobre esta pena, bem como a prisão perpétua, os trabalhos forçados, o banimento e as penas cruéis. Logo, tal proibição é um 
desdobramento da proteção ao direito à vida e que coaduna também com o Artigo $5^{\circ}$ da Declaração Universal de Direitos Humanos, a qual determina que: "Ninguém será submetido à tortura, nem a tratamento ou castigo cruel, desumano ou degradante". Apesar de tal tutela, sabe-se que alguns países adotam a prisão perpétua e a pena de morte, como, por exemplo, os Estados Unidos e a China. Esse fato demonstra que ainda existe um longo caminho a ser trilhado na busca pela proteção do direito à vida e, por conseguinte, dos direitos humanos.

\title{
5 A universalização dos direitos humanos
}

É devido à grande importância dos direitos humanos que se fala em universalizar tais direitos. Essa universalização consiste em proteger e assegurar os direitos e garantias do indivíduo em qualquer país resguardado pela comunidade internacional. A proteção deixa de ser aplicada apenas no âmbito interno e passa a ser estendida internacionalmente, sendo um imperativo de sobrevivência para a humanidade. Os direitos humanos devem ser reconhecidos e protegidos em todo e qualquer Estado e aquele que assim não proceder não poderá reclamar a legitimidade de um poder estatal.

\begin{abstract}
Cuida-se de um elenco de bens jurídicos protegidos independentemente de quaisquer particularismos de nacionalidades ou de matriz cultural: vida, integridade física e moral pessoal, garantias judiciais básicas. Estas se expressam através de normas que vinculam, efetivamente, o Estado a cumprir obrigações com relação à comunidade internacional. A obrigação de respeito pelos direitos humanos é erga omnes, o que implica num dever de solidariedade entre todos os Estados, a fim de garantir o mais rapidamente possível uma proteção universal efetiva dos direitos humanos (XV CONGRESSO, 2006, p. 08).
\end{abstract}

O processo de globalização pelo qual o mundo tem passado nas últimas décadas contribuiu para a disseminação da necessidade de se assegurar os direitos humanos. Trata-se de num intenso relacionamento entre os indivíduos e diversas instituições em várias áreas, como, por exemplo, a economia, a ciência, a tecnologia e a comunicação. Com isso, transforma-se o mundo num intenso território e, por conseguinte, difundindo os direitos humanos como pertencentes a qualquer indivíduo independente do país em que esteja, ultrapassando os limites territoriais e de soberania. 
Ademais, em tese, a meta primordial de um Estado-nação é proteger os cidadãos que nele vivem e a necessidade dessa proteção deve seguir padrões coerentes e aceitos internacionalmente. Isso levou grande parte dos Estados modernos a terem como parâmetro a Declaração Universal de Direitos Humanos.

Contudo, tal proteção é ameaçada e se contrapõe ao princípio da soberania e da não intervenção, o qual garante que os Estados podem se autogovernarem sem intervenções externas. $\mathrm{O}$ que lhes garantem o direito de legislarem e terem suas próprias regras e que muitas vezes podem desrespeitar o que está tutelado na Declaração Universal de Direitos Humanos, quando um Estado, por exemplo, decreta a pena de morte para determinados crimes.

Além do que, um obstáculo central, na sociedade contemporânea, a ser considerado na universalização do direito à vida e dos direitos humanos é a diversidade cultural existente entre os países. A Declaração de Viena, editada no ano de 1993, reafirmou o caráter universal dos direitos humanos, até mesmo além das características culturais de um país, conforme dispõe o Artigo 50:

Todos os direitos humanos são universais, indivisíveis, interdependentes e inter-relacionados. A comunidade internacional deve tratar os direitos humanos globalmente, de maneira justa e equânime, com os mesmos parâmetros e a mesma ênfase. As particularidades nacionais e regionais e bases históricas, culturais e religiosas devem ser consideradas, mas é obrigação dos Estados, independentemente de seu sistema político, econômico e cultural, promover e proteger todos os direitos humanos e liberdades fundamentais (ONU, 1993).

Essa é a questão conflitante alvo de várias discussões atualmente. Como universalizar direitos que são tidos como primordiais para o ser humano, sobretudo o direito à vida, e, ao mesmo tempo, sem invadir a soberania e os costumes de um país? A própria Declaração de Viena oferece a solução para esse empasse ao defender que as particularidades nacionais e socioculturais devem ser consideradas. Todavia, a primeira obrigação é a defesa do direito à vida e, por conseguinte, a proteção dos direitos humanos independente de questões políticas, econômicas e culturais nacionais ou locais.

Mas o que se indaga é como proceder quando mesmo diante dessa determinação a violação ao direito à vida permanece, principalmente em se tratando de tradições culturais?

Diante das particularidades apresentadas pela cultura de cada povo 
criou-se a teoria do relativismo cultural no século XIX, no intuito de que uma cultura não fosse comparada com a cultura ocidental e, por ser diferente dessa, considerada como inferior. Segundo Torres (2010, p. 65) seria o "não-julgamento do modo de ser das diversas sociedades existentes no mundo, no que diz respeito a seus hábitos, sistemas, religiões, ritos, ou seja, à sua cultura em geral, em comparação à cultura das sociedades consideradas ocidentalizadas".

Os costumes de alguns povos do Oriente Médio, por exemplo, causam repúdio e são condenados pelo Ocidente. Mas como relativizar tais costumes quando se trata de ferir o direito à vida, o bem maior do ser humano?

Como exemplo, apresentam-se duas situações de violação do direito à vida. Violações que acontecem dentro do espaço sociocultural nacional.

A primeira situação é a de afronta à proibição de tratamento desumano ou degradante vivida por meninas de 0 a 14 anos em algumas regiões como a África, o Oriente Médio e o sudeste asiático. Elas são submetidas ao procedimento de clitoridectomia, o qual consiste na retirada do clitóris, para que no futuro essas mulheres não venham, dentre outras coisas, a sentir prazer sexual. Essas cirurgias são realizadas de forma muito precária, colocando em risco a vida dessas meninas e, muitas vezes, resultando em esterilidade ou até mesmo a morte.

Para o Ocidente essa prática é chocante. Mas não é assim nas regiões onde é praticada. A mulher é totalmente submissa e os povos que fazem a clitoridectomia acreditam que ela ajuda a manter a virgindade das solteiras. Além disso, reforçaria a identidade do grupo. Apesar da dor após a operação e da humilhação, as mulheres não se atrevem a reclamar. "Quando perguntadas sobre o conhecimento das leis dos Direitos Humanos, elas respondem que apenas conhecem as leis dos maridos", diz a queniana Wanjira Muigai (MENAI, 1997).

A segunda situação de violação do direito à vida é a questão da pena morte por meio do apedrejamento aplicada nos países islâmicos, como é o caso do Irã, em casos de relações sexuais mantidas por pessoas solteiras ou de adultério. Como está descrito no Código Penal iraniano:

Ao homem se enterra em um buraco até a cintura enquanto a mulher é enterrada até os ombros [...]. As pedras não devem ser tão grandes para que a pessoa morra com poucos golpes, nem tão pequenas que não se possa considerá-las pedras. Se o condenado é capaz de escapar com vida não se tenta matá-lo uma se- 
gunda vez (o homem tem a vantagem de ter ar da cintura até os ombros e, por vezes, ele sobrevive). Caso morra por outra causa, o alvo das pedras será seu cadáver (LA VANGUARDIA, 2010).

O comum é que diante de situações tão cruéis os organismos internacionais de defesa do direito à vida, dos direitos humanos e os principais países ocidentais fazerem algum tipo de pressão política-econômico-midiática pela modificação dessas penas e, às vezes, pode dar certo, como o caso da pena de apedrejamento de Sakineh Mohamadi Ashtiani, que acabou sendo evitada no Irã.

A realidade que ora se impõe é que mesmo diante de documentos internacionais que tutelam o direito à vida, principalmente a Declaração Universal dos Direitos Humanos, e da luta pela universalização dos direitos humanos, na prática os crimes continuam acontecendo no interior dos países justificados por suas leis internas e pelos seus costumes culturais. Em curto prazo, não existe uma solução para esse problema. No entanto, deve-se enfatizar que o direito humana a vida é universal e indispensável para a manutenção e desenvolvido de qualquer modelo de sociedade, cultura, nação e Estado. Por isso, esse direito tem que ser aplicado a todos os indivíduos da espécie humana, da concepção à morte natural, independente das exigências socioculturais nacionais. De um lado, é necessário respeitar e valorizar a diversidade cultural existente atualmente no mundo, com suas várias e multicores étnicas, linguísticas, religiosas e sociopolíticas. Do outro lado, diante do princípio fundamental do direito à vida, não se pode aceitar que, em nome da diversidade cultural, uma cultura, uma nação ou um modelo de Estado possa discriminar grupos humanos e que essa discriminação alcance o nível da exclusão radical da vida por meio da morte. Por isso, é necessário buscar um equilíbrio que mantenha a diversidade e a autonomia das culturas, mas, ao mesmo tempo, garanta e promova o princípio fundamental do direito à vida.

\section{Considerações finais}

Diante do exposto, reforça-se que, de um lado, é necessário respeitar e valorizar a diversidade cultural existente atualmente no mundo, com suas várias e multicores étnicas, linguísticas, religiosas e sociopolíticas. Do outro lado, diante do princípio fundamental do direito à vida, não se pode aceitar que, em nome da diversidade cultural, uma cultura, uma nação ou um modelo de Estado possa discriminar grupos humanos e que essa discriminação alcance o nível da 
exclusão radical da vida por meio da morte. Por isso, é necessário buscar um equilíbrio que mantenha a diversidade e a autonomia das culturas, mas, ao mesmo tempo, garanta e promova o princípio fundamental do direito à vida.

Por fim, à guisa de conclusão, se reconhece a relevância do princípio fundamental do direito à vida e a necessidade de se propagar um movimento pela sua universalização, assegurando que cada indivíduo tenha sua vida protegida e resguardada em qualquer território, independente da nação a qual pertença. Ao mesmo tempo, se reconhece que na atualidade a proteção e garantia do princípio fundamental do direito à vida tem sido falha e se observam vários casos de atentados a esse direito, pois além de falhar na proteção falha-se também na educação para a vida e na punição dos indivíduos e das estruturas sociais culpadas pela violação do direito universal a vida.

\section{Referências}

AGOSTINI, Nilo. Bioética e ética médica: educar para uma ética da vida. In: GIACOIA JÚNIOR, Oswalvo; RAMIRO, Caio Henrique Lopes; RICCI, Luiz Antonio Lopes. Responsabilidade e futuro: bioética, biopolítica, biopoder e os desafios para a reflexão e a ação. São Paulo: LiberArs, 2015, p. 31-46.

BRAKEMEIER, Gottfried. O ser humano em busca de identidade. São Leopoldo: Sinodal, 2002.

BRASIL. Constituição da República Federativa do Brasil. Distrito Federal: Senado, 1988.

BRASIL. Código Civil. Brasília: Palácio do Planalto, 2002. Disponível em: <http:// www.planalto.gov.br/ccivil_03/leis/2002/L10406.htm>. Acesso em: 29 dez. 2015.

BRASIL. Lei $\mathbf{n}^{0}: \mathbf{9 . 4 3 4 / 9 7}$. Lei de Transplantes. Dispõe sobre a remoção de órgãos, tecidos e partes do corpo humano para fins de transplante e tratamento e dá outras providências. Brasília: Palácio do Planalto, 1997.

FUKUYAMA, Francis. Nosso futuro pós-moderno. Rio de Janeiro: Rocco, 2003.

INTERNATIONAL BAR ASSOCIATION (Reino Unido) (Org.). Direitos Humanos 
na Administração da Justiça: um Manual de Direitos Humanos para Juízes, Procuradores e Advogados. Londres: International Bar Association, 2010.

LA VANGUARDIA. O apedrejamento divide o Islã. In: Veja, São Paulo, out. 2010.

MENAI, Tânia. A retirada do clitóris é comum na África. In: Superinteressante, São Paulo, n. 118, jul. 1997.

ONU. Declaração de Viena. Viena: 1993. Disponível em:<http://www.dhnet.org. br/direitos/anthist/viena/viena.html>. Acesso em: 21 dez. 2015.

RAMOS, André de Carvalho. Curso de direitos humanos. São Paulo: Saraiva, 2014.

SANTOS, Ivanaldo. A educação para a vida: um direito do cidadão. In: SANTOS, Ivanaldo; POZZOLI, Lafayette. Direito e educação: uma abordagem interdisciplinar. São Paulo: Letras Jurídicas, 2014, p. 43-58.

TAURECK, Bernhard H. F. A dignidade humana na era de sua supressão. São Leopoldo: Nova Harmonia, 2007.

TORRES, Mateus Gamba. O Absolutismo Cultural e a Clitoridectomia. In: Percursos, Florianópolis, v. 11, n. 1, p. 64-72, jul. 2010.

UNESCO. Declaração Universal dos Direitos Humanos. Brasília: 1998.

XV CONGRESSO NACIONAL DO CONPEDI. Direitos humanos e pluralismo cultural: uma discussão em torno da questão da universalidade. 15, 2006, São Paulo: Publica Direito, 2006.

ZILLES, Urbano. Pessoa e dignidade humana. Curitiba: Crv, 2012. 